\title{
Sensitivity and Risk Analyses for the Evaluation of Transport Investments
}

\author{
Giuseppe Inturri ${ }^{1}$, Matteo Ignaccolo ${ }^{1} \&$ Salvatore Caprì ${ }^{1}$ \\ ${ }^{1}$ Department of Civil and Environmental Engineering, University of Catania, Catania, Italy \\ Correspondence: Giuseppe Inturri, Department of Civil and Environmental Engineering, University of Catania, \\ 95124 Catania, viale Andrea Doria 6, Italy. Tel: 39-9-5738-2935. E-mail: ginturri@dica.unict.it
}

Received: January 20, 2012 Accepted: May 16, 2012 Online Published: July 11, 2012

doi:10.5539/emr.v1n2p16 URL: http://dx.doi.org/10.5539/emr.v1n2p16

\begin{abstract}
Access to Structural Funds of the European Union for the realisation of infrastructural projects having a value in excess of $50 \mathrm{M} €$ requires advance preparation of economic and financial analyses including sensitivity and risk analyses for the probabilistic evaluation of uncertainties linked to the investment financing. This work illustrates the techniques and methods necessary in order to carry out such analyses, with reference to the case study of the Catania underground railway line.
\end{abstract}

Keywords: sensitvity analysis, risk analysis, Montecarlo method, transport investment funding

\section{Introduction}

Structural Funds are one of the main European Union financial instruments contributing to the removal of economic and social imbalance among its regions, thus favoring economic and social cohesion. Council Regulation (EC) n. 1083/2006 establishes the procedure to obtain the Structural Funds co-financing infrastructural projects; when the value of the investment is over $50 \mathrm{M€}$, the procedure requires additional documentation in order to evaluate the project.

The aim of this work is to illustrate some of the techniques that are necessary in order to carry out the analyses required for the drawing up of these documents, with particular reference to sensitivity and risk analyses. These are techniques that are able to evaluate, both the probability a project has of achieving a satisfactory economic-financial performance (in terms of Net Present Value or Internal Rate of Return on Capital) and the variability of the result as compared to the estimate carried out.

Risk analysis, in particular, is performed by means of a methodology based on the Montecarlo method, a methodology of statistical simulation that is frequently used in the scientific field, and with reference to the actual case of the underground line project of the Catania Circumetnea Railway.

\section{The 3 rocedure for Accessing Community Funds}

In order for the Funds to participate in financing an infrastructural investment, the member State or the management body sends a series of information to the EC (2006), among which:

- $\quad$ analyses of the costs and benefits, including financial ones, risk evaluation and indications of the economic validity of the project;

- $\quad$ analyses of the socio-economic costs and benefits of the project;

- $\quad$ direct and indirect effects on the employment situation;

- $\quad$ elements leading to an evaluation of the environmental impact and respect for the community regulations in environmental matters.

The proponent, then, submits a technical-economic study to the EC called a 'Great Project File', whose fundamental contents are a financial analysis, an economic analysis and a risk and sensitivity analyses (Florio, 2007).

\subsection{Economic and Financial Analyses}

Both analyses use a technique for forecasting the results of a public investment, that falls into the category of costs-benefits analysis (CBA). It is used to evaluate whether the project will determine a benefit or a cost to the 
community (Boardman, 2006).

The CBA judges appropriateness not only on criteria of a financial kind but also on economic and social advantage criteria, calculated from the results of a financial analysis by means of appropriate corrections to arrive at the total costs and social benefits linked to the project under examination.

There are frequent cases of projects that are 'economically' advantageous but not 'financially': one thinks of the case of a road with no tolls that, although being highly useful for the areas that it serves (in terms of development of economic activity and social advantages) does not produce any kind of financial return.

In a sector like public transport, characterised by many public tariffs, it is crucially important to distinguish between:

- $\quad$ costs sustained by the user

- $\quad$ production costs

The former can be considered as being 'demand costs' that, in the case of public transport systems, are the fares paid by the users of the service, while the latter, which measure the financial resources spent in the realisation, operation and maintenance of the finished project, can be defined as 'supply costs'.

As regards the benefits, from a financial point of view it is sufficient to consider the income from fares while from an economic point of view reference is made to the concept of the user's willingness to pay.

The CBA takes the form of a table from which it is possible to calculate some synthetic result indexes that measure the performance of the project in financial and economic terms. Among the most frequently used indexes we should consider the Net Present Value (NPV) (Note 1), equal to the discounted sum for each year of the cash flow balances and the Internal Rate of Return (IRR), equal to the discount rate that corresponds to a nil NPV.

Generally, in the first m years during which works are carried out (construction site phase), the impacts $I$ are only negative (investment costs), while in the following n-m years, even with negative impacts $C_{t}$ (operating and maintenance costs) there is a prevalence of positive impacts $B_{t}$. If $V_{n}$ indicates the residual value of the investment and is considered as a positive impact that matures in the final years of service life, the NPV expression is as follows:

$$
N P V=-\sum_{t=1}^{m} \frac{I_{t}}{(1+i)^{t}}+\sum_{t=m+1}^{n} \frac{B_{t}-C_{t}}{(1+i)^{t}}+\frac{V_{n}}{(1+i)^{n}}
$$

being $i$ the discount rate and $t$ the general running year.

Given that in the early years there will probably be a negative flow, due to the expenses of the initial investment, while only in the following periods will there be income, and because the discounting process attributes a greater weight to the present flows compared to the future ones, the choice of the time horizon and the discount rate influence the calculation of the NPV, as shown in Figure 1.

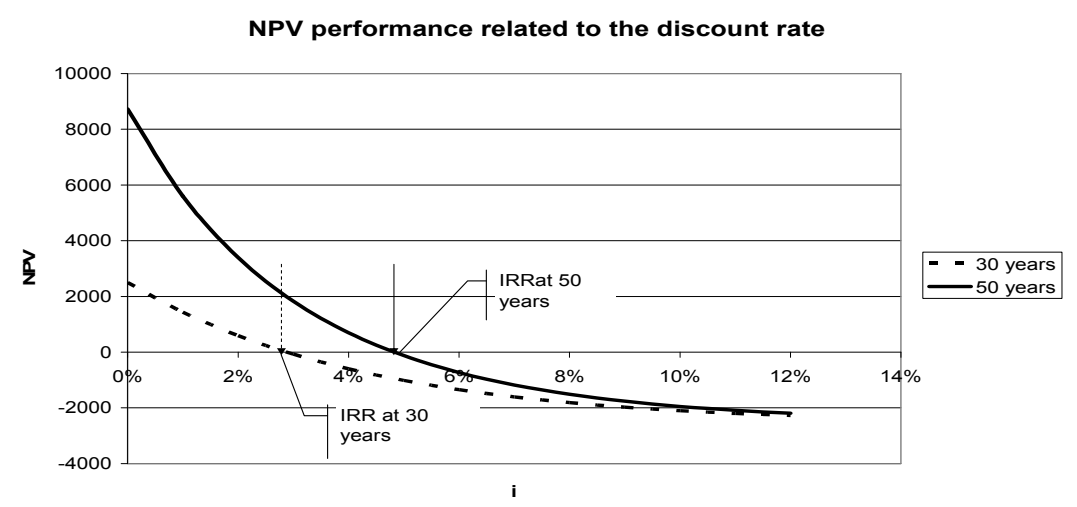

Figure 1. NPV performance as a function of the discount rate for different durations of the economic life of the project 


\section{Risk and Sensitivity Analyses}

It is obvious how the results of an ACB involve a degree of uncertainty deriving from the hypotheses carried out on the values of the variables and the parameters used as the basis for calculating the indicators, such as travel demand, operation and construction costs or traffic incomes.

Sensitivity and risk analyses constitute two means of support for the benefits-costs analyses when dealing with uncertainties.

The sensitivity analysis evaluates the impact on the calculated financial and economic indexes of hypothesised changes in the estimated values of the variables that determine costs and benefits.

The risk analysis consists in a study of the probability that the project will attain a satisfactory performance (in terms of synthetic indicators), as well as the variability of the results as compared to the best previous estimate. The recommended procedure for studying risk establishes that it is preceded by and based on an analysis of sensitivity. In practice, the probability distribution of the CBA indicators incorporates the dispersion of variables identified as critical by the sensitivity analysis.

The analysis of risk is more frequently applied to financial indicators, in that they can be more directly correlated to the sum of the resources required from the financing body.

We will go on to show the application of the sensitivity and risk analyses, carried out in accordance with the request for the confirmation of the structural funds co-financing of the construction of the underground line of the Catania Circumetnea Railway.

\subsection{Economic and Financial Analyses}

The Circumetnea Railway is the only surviving narrow gauge railway line in Sicily. It began life in 1880 when a railway network framework was being outlined in Sicily. The first stretch of line from Catania Borgo to Adrano opened in 1895. The present route, $110 \mathrm{Km}$ long, leaves Catania, winds up the slopes of the volcano to a height of almost $1000 \mathrm{~m}$ above sea level and then descends seawards to the station of Riposto, passing through numerous towns and villages (see Figure 2).

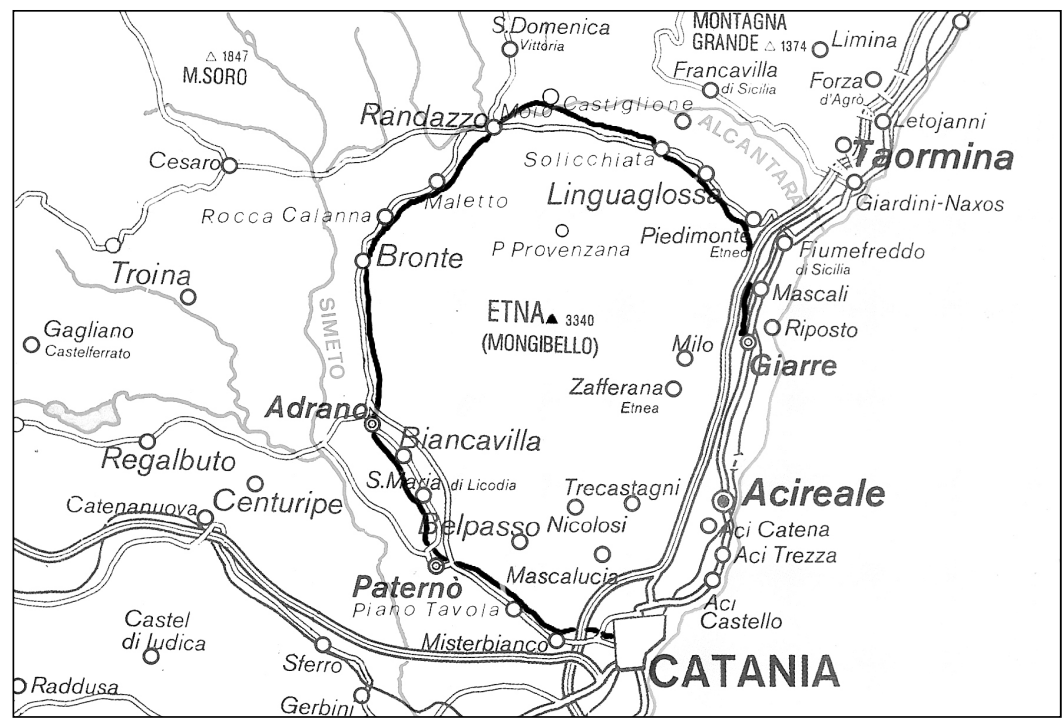

Figure 2. Present lay-out of the narrow gauge Circumetnea Railway

In recent decades demographic changes in the population of Catania and the towns of the Etna conurbation have led to a great deal of commuting and consequent congestion of the road network due to an increased use of private transport. This has meant that the Circumetnea Railway has had to redefine its role and services and has therefore led to intense planning and development based on two main objectives:

- the transformation and specialisation of the urban service by means of the construction of an underground railway line

- the development and modernising of the present extra-urban line between the towns of Paternò and Adrano, a distance of about $15 \mathrm{Km}$.

With regard to the first objective, works are already underway, with the existing line being rebuilt underground, 
$3.8 \mathrm{Km}$ having been partially completed and the service will eventually be expanded by means of the construction of four new stretches of railway line in tunnels having the characteristics of an underground system, with a total length of $9 \mathrm{~km}$. The first two stretches, Galatea-Giovanni XXIII $(0.9 \mathrm{~km})$, at present in the construction phase, and Giovanni XXIII-Stesicoro $(1.2 \mathrm{~km})$, will extend the existing line into the centre of Catania while the other two, Borgo-Nesima $(3.1 \mathrm{~km})$ and Nesima-Misterbianco $(4.0 \mathrm{~km})$, will connect the present underground with the suburban areas to the north-west of the city and the town of Misterbianco where there is an important residential and commercial area. The building specifications of this project, in line with those already completed, are a double track with normal gauge and electric traction with $3 \mathrm{KV}$ direct current (see Figure3).

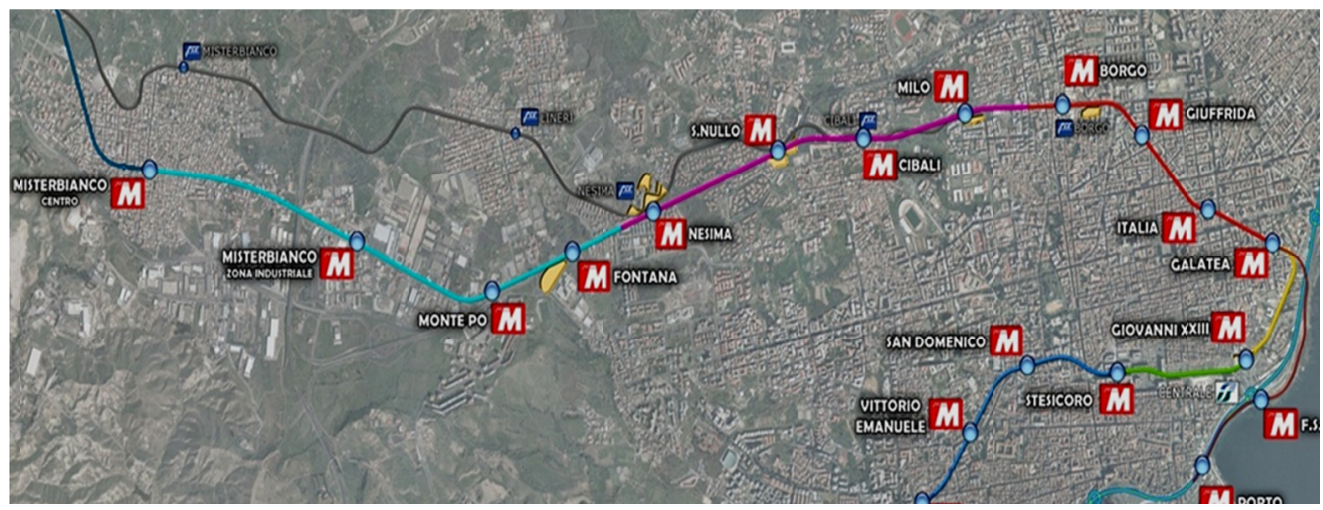

Figure 3. Planimetry of the programmed projects

The second objective is also underway between Paternò and Adrano. The present stretch, with a single narrow gauge line, will be modernised to a single line with specifications that will subsequently permit it to be transformed into a normal gauge with electrification at $3 \mathrm{KV}$ direct current. The features of the railway track, the electric feeding line, the safety system, the railway signalling system and technological station equipment, apart from an adequate and modern service, will mean that passengers travelling from the Paternò and Adrano stretch towards the Catania underground system will not have to break their journey.

The total cost of the works is equal to 175 million euro financed exclusively from public funds, the greater part coming from the funds provided by Italian Law 211/92 and 78.75 million euro from Community sources through the FESR structural funds. The rate of community financing is at present $45 \%$ of the public expenditure. The total cost of the work described above is equal to 255.7 million euro, considering also the purchase of 4 traction units (see Figure 4).

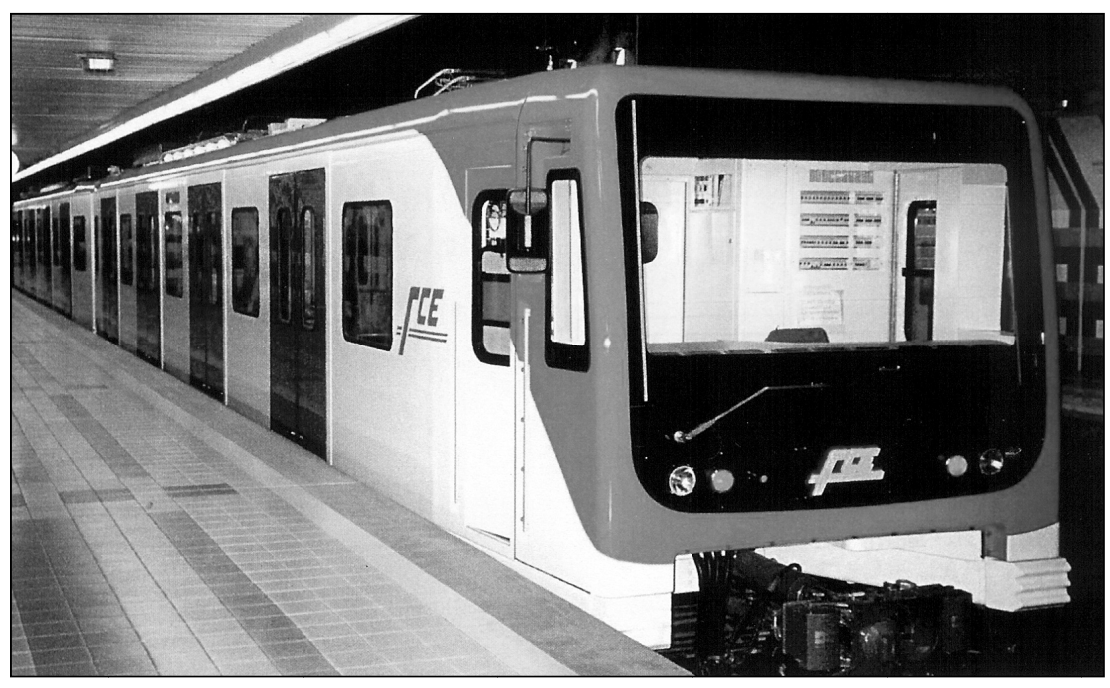

Figure 4. Traction unit of the Catania Underground 
The projects relating to the stretches Galatea - Giovanni XXIII - Stesicoro, Borgo - Nesima - Misterbianco and Paternò - Adrano are of the type laid down for the so-called 'Great Projects', in accordance with article 40 of Council Regulation (EC) n. 1083/2006 for access to community funds, for which the relative forms and files have already been completed and sent to the European Commission for modification or confirmation of the rate of community financing.

\subsection{Sensitivity Analysis}

As has already been said sensitivity analysis falls within the category of methods used for the treatment of risk in investment analysis (Saltelli et al., 2008). It aims at quantifying the effects induced on a cash flow by variations in the input variables, and therefore on the final outcome of the project calculated by means of the NPV. In essence, it supplies the decision maker with analysis elements regarding what happens if some parameters differ from the basic case.

The uncertainty that characterises the variables used for estimating costs and revenue, can be described as a probability distribution. The high number of variables that influence the final results and the complexity of the analyses that it would otherwise be necessary to carry out, make it necessary to select some of the so-called 'critical' variables, that is those whose departure from the best estimate value

The European Commission (2008) suggests to consider as critical variables those for which a variation of (more or less) $1 \%$ gives place to a corresponding variation of $1 \%$ (one percentage point) of the IRR or $5 \%$ of the basic rate of the NPV.

The procedure to be followed for the analysis of sensitivity includes:

- the identification of the variables used that are affected by uncertainty

- the analysis of the existing correlation between the variables

- the evaluation of the elasticity of the variables for the calculation of the NPV

- the identification of the critical variables

The variables that have been used for the financial analysis are:

- $\quad$ passengers' mobility demand per year, divided into its various components of diverted demand (from private and public transport) and generated demand

- the operational costs divided into the running costs of the service and the maintenance costs of the infrastructure and rolling stock

- the fares established for the use of the service by customers with season tickets or one-way tickets.

There are undoubtedly some relationships of dependence between the used variables.

This is the case with the operational costs that depend on the passenger demand that must be satisfied. It is supposed that the transportation capacity of the line is adapted proportionally to the demand. This is obtained by modifying the train transit frequency and consequently increasing running costs.

In reality, if we divide the running costs into fixed costs, that is not depending on the production level of the service, and variable costs, only the latter can be considered as depending directly on demand while, in the short term, the fixed costs are independent.

Figure 5 shows the law of dependence between the operational costs and demand that have been assumed in the NPV calculation model. The stepped curve represents, with each step, the cost increase produced by the introduction of a new traction unit to satisfy the need for capacity induced by growing demand. The continuous linear curve represents the approximation used in the NPV calculation model. 


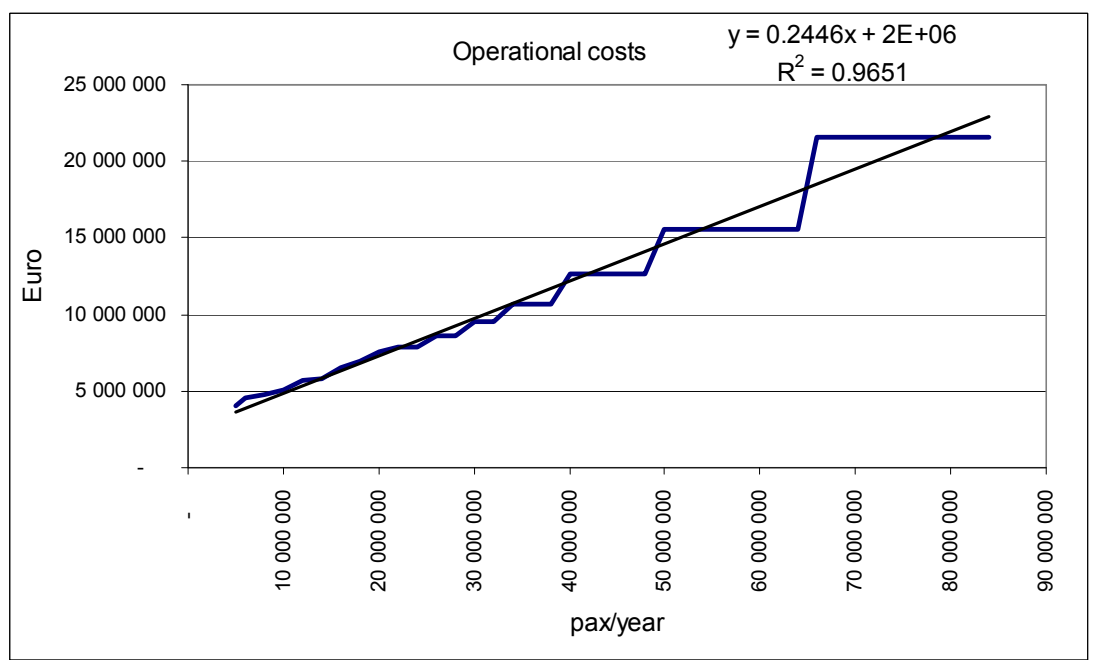

Figure 5. Operational costs related to the demand for transport

It is possible to identify another law of dependence between the fares applied and the consequent level of demand. It is well-known that for all goods and services and for each class of user it is possible to identify a different sensitivity of demand to variations in price. When a variation in the quantity demanded of more than $1 \%$ corresponds to a price variation of $1 \%$, it is called elastic demand, when the variation is less than $1 \%$ it is called static demand (or inelastic). In particular, price elasticity of demand is calculated by means of the expression:

$$
E_{D}=\frac{\frac{|\Delta Q|}{Q_{0}}}{\frac{|\Delta P|}{P_{0}}}=\frac{|\Delta Q|}{Q_{0}} \frac{P_{0}}{|\Delta P|}
$$

$P$ being the price and $Q$ the demand. This expresses, therefore, the percentage variation of the demand compared to a percentage variation in the price.

The price elasticity of demand for public transport in Catania has been evaluated by analysing a series of historical data relatied to the Municipal Transport Company (AMT) that runs the public transport service in the Municipality of Catania and in some of the neighbouring areas.

Figure 6 shows a set of points whose co-ordinates refer to passenger traffic recorded in various years and the relative fares. The fare has been index-linked using a number of ISTAT cost of living indexes. The same figure shows an exponential trend line that approximates the trend of the demand curve related to the fare.

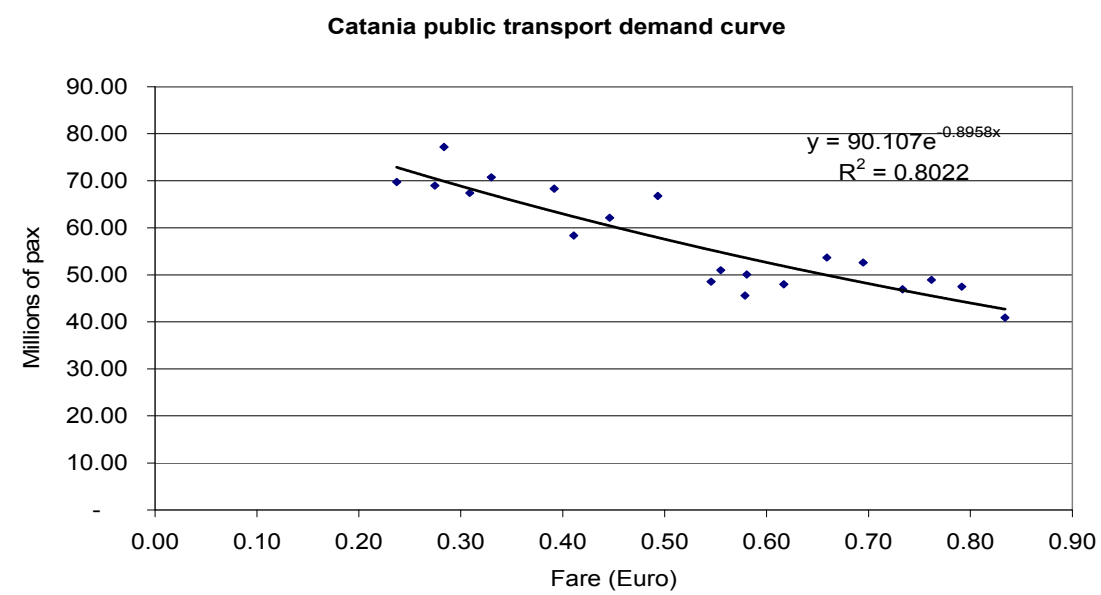

Figure 6. Catania public transport demand curve 
Hypothesising that the demand for public transport on the planned underground line demonstrates the same price elasticity shown by the AMT demand, Figure 7 shows the demand curve of public transport on the planned underground line.

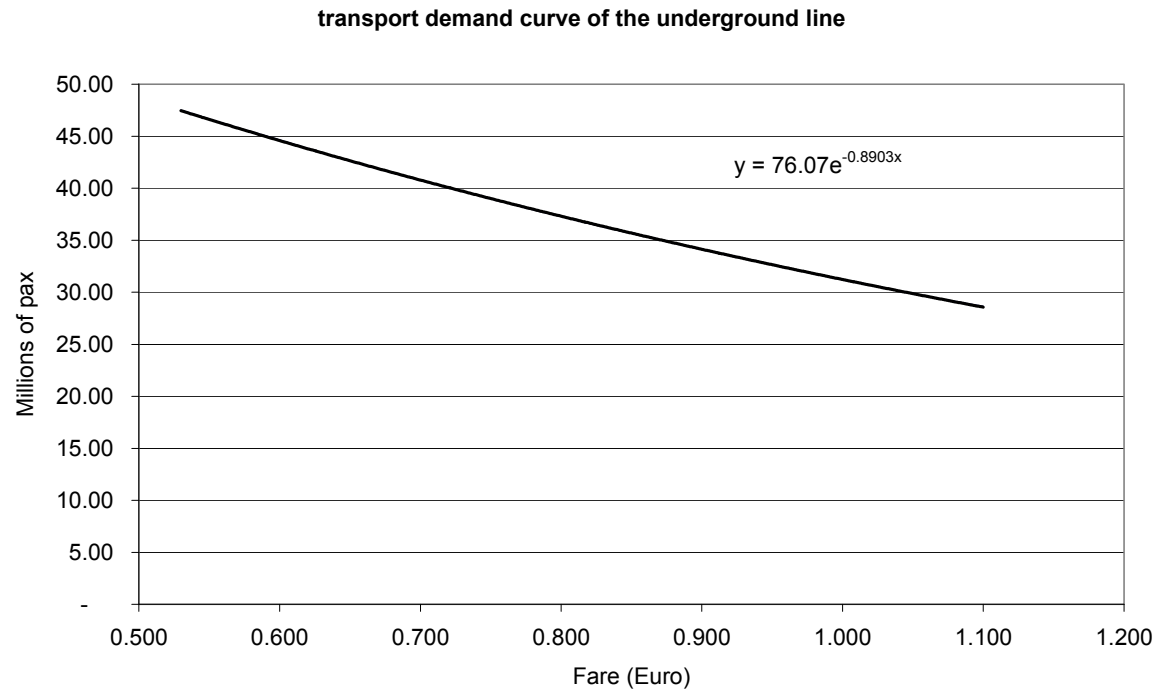

Figure 7. Transport demand curve of the underground line

Once the variables and their dependence have been identified, the procedure of sensitivity analysis establishes that the input variables chosen be made to vary from $50 \%$ to $150 \%$ as compared to the basic case. Within the variation range corresponding to each step increase of $10 \%$, this calculates the corresponding output value, in this case the NPV value, both in absolute terms and in terms of percentage variations compared to the basic case. The results for total demand are shown in Figure 8 and Figure 9.

The results show a more or less linear variation and marked agreement of the NPV to the demand. In percentage terms a variation of little less than $4 \%$ of the NPV corresponds to a variation of $20 \%$ in the demand.

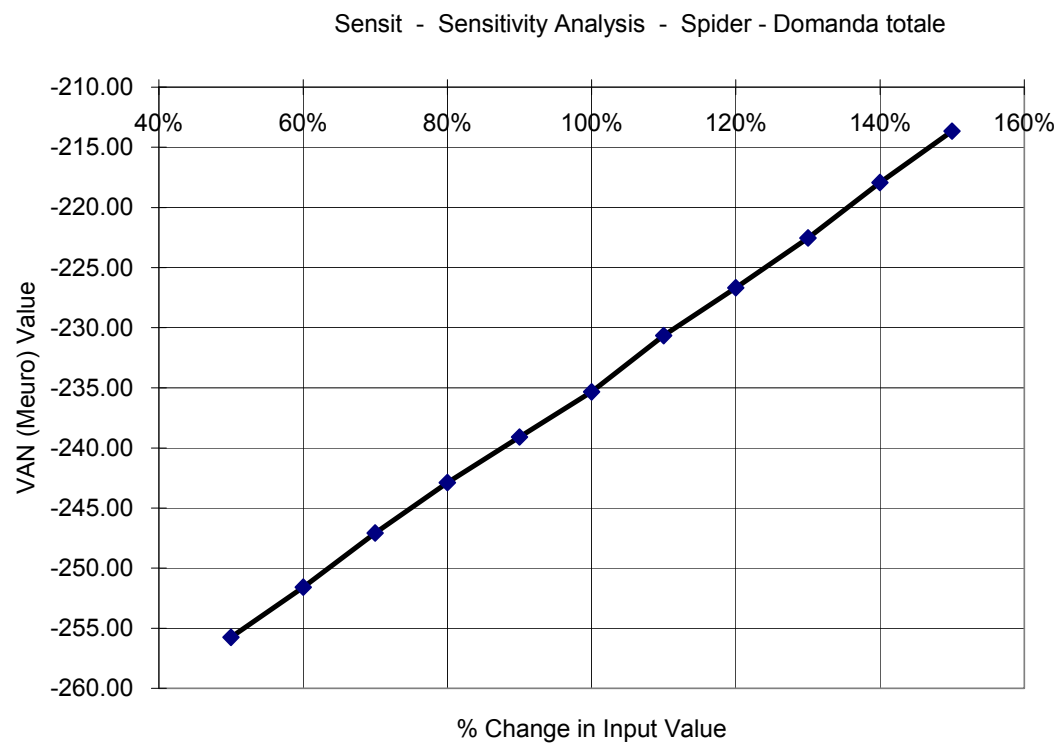

Figure 8. Analysis of sensitivity to the total demand of the NPV in absolute value 


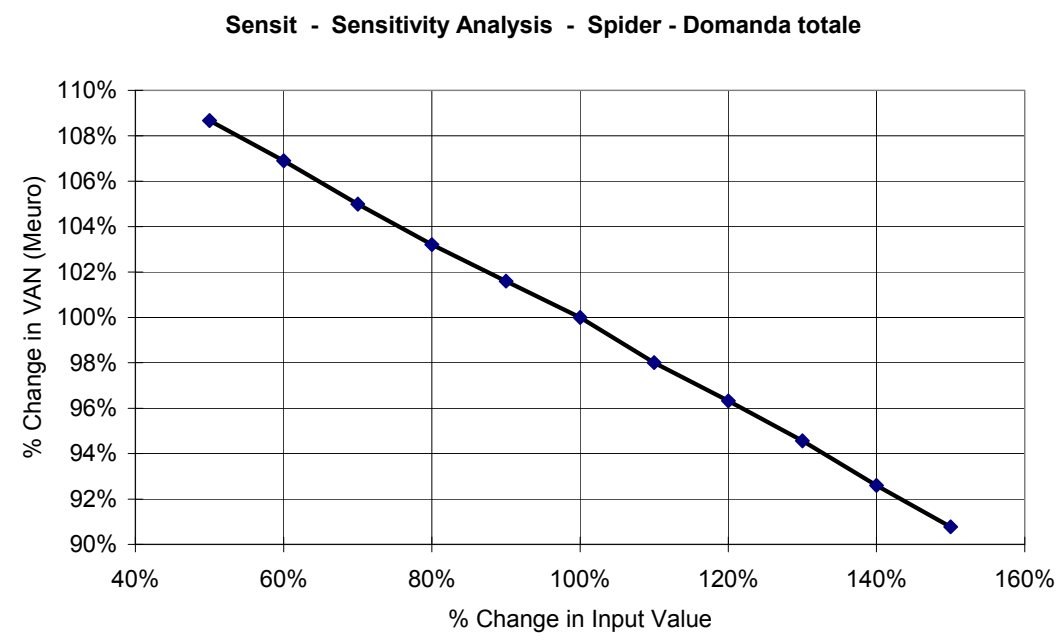

Figure 9. Analysis of sensitivity to the total demand of the NPV in percentage terms

As regards the variable fare, the fare of the non-season ticket holder was assumed as the independent variable, that is the fare for a one-way ticket equal to 0.77 euro in the basic case and considering that with one ticket the user performs on average 1.2 journeys.

The fare of the season ticket holder is calculated considering a fare unit of about $40 \%$ of the one-way ticket fare (16 euros for a monthly season) and hypothesising that the holder performs 52 journeys a month when the service begins to then arrive at 62 monthly journeys at the end of the service life of the line.

Figure 7 shows the law of dependence between the fare and the demand assumed as the hypothesis in the NPV calculation model. This means that in agreement with each of the percentage variations of the fare compared to the basic case, the demand assumed for the calculation will be modified compared to the basic case, according to this law of dependence. It follows that in its turn a variation in the demand will produce a consequent variation in the operational costs and therefore in the net revenue.

Figure 10 and Figure 11 show the results of the analysis of the elasticity of the NPV to the fare.

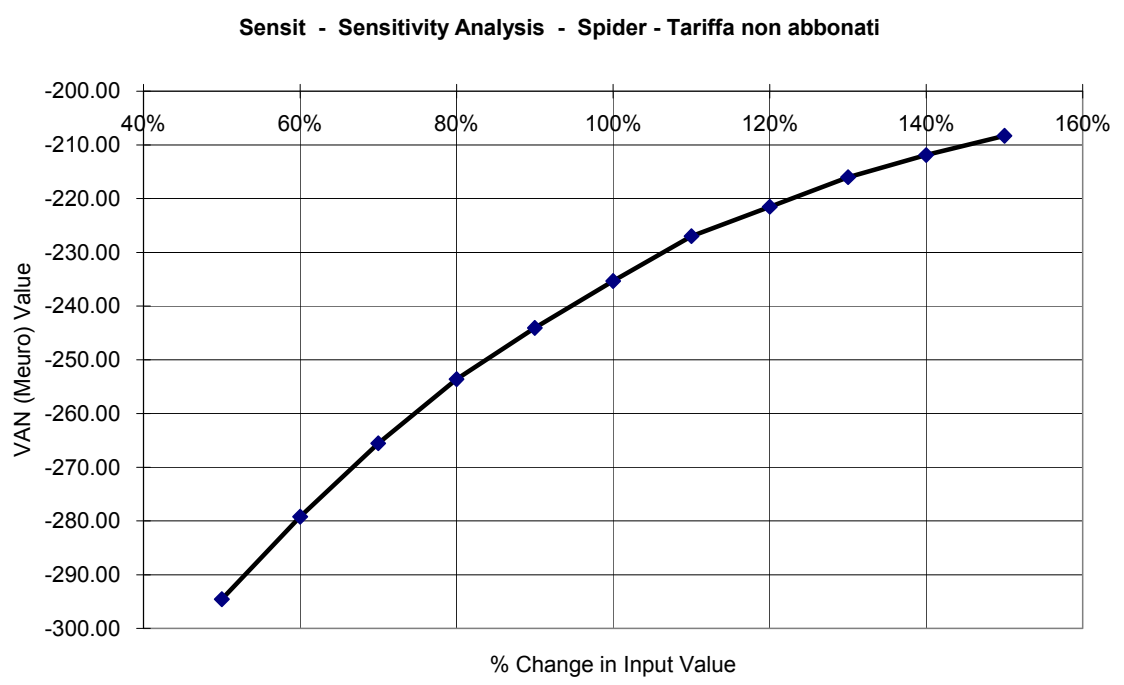

Figure 10. Analysis of sensitivity of the NPV to the fare in absolute terms 


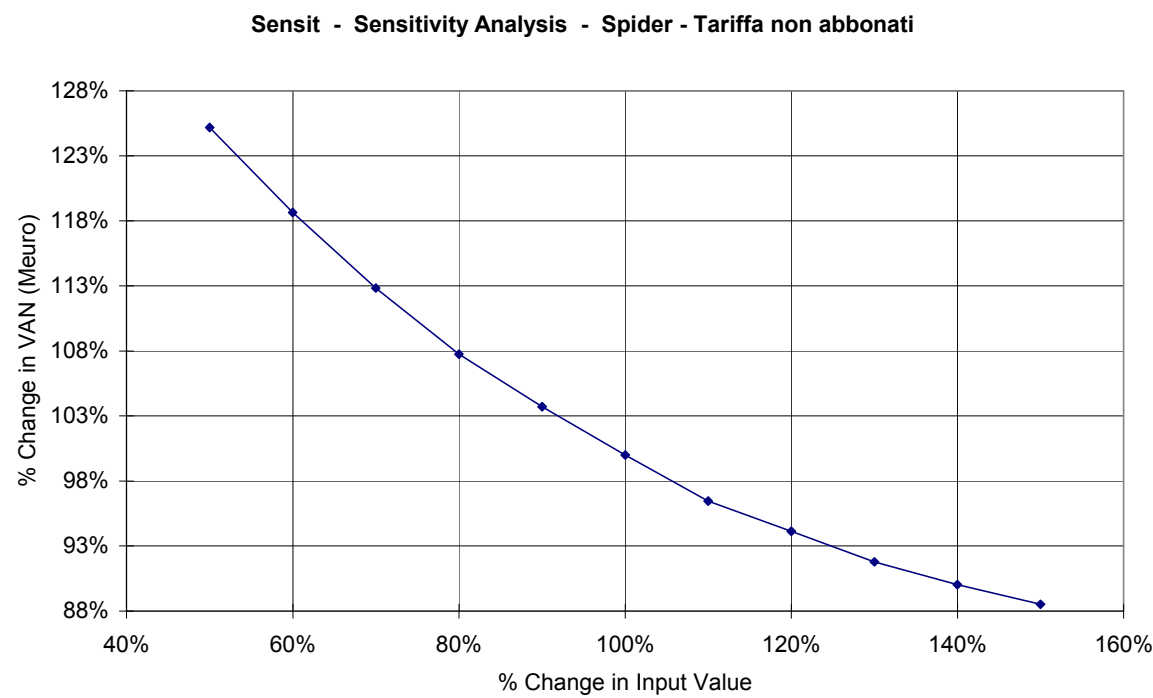

Figure 11. Analysis of sensitivity of the NPV to the fare in percentage terms

The curves indicate a high non-linearity in the variation of the NPV to the fare, due to the dependence of demand on this latter. In fact because of the elasticity of demand to the fare, fare increases produce a reduction in demand and therefore a reduction in the growth of revenue. In percentage terms, a positive variation of $20 \%$ of the fare corresponds to a $6 \%$ increase of the NPV while a reduction of $20 \%$ in the fare corresponds to an $8 \%$ decrease in the NPV.

If we assume the suggestions made in the 'Guide to the costs-benefits analysis of investment projects' (EU, 2008) as the criteria for the identification of the critical variables, it would be necessary to choose only those variables for which a variation of (more or less) $1 \%$ gives rise to a corresponding variation of $5 \%$ in the basic value of the NPV.

From an examination of the results of the sensitivity analysis carried out above, none of the variables responds to the criteria in such a way as to be considered critical. We find ourselves, therefore, in a situation in which the successive phase of risk analysis would not be strictly necessary.

Nonetheless, it is considered necessary to carry out the risk analysis just the same assuming total demand and the fare as sensitive variables.

As far as demand is concerned, during mobility analyses for the basic case certain hypotheses regarding the diverted demand and generated demand have been assumed, that, although very prudently quantified, have nevertheless maintained a high degree of uncertainty. The same is true for the difficulty in forecasting over such a long period, the entity and quality of the policies that will be adopted by local and national authority administrations as regards transport planning measures.

\subsection{Risk Analysis}

As has already been said, the NPV of a project depends on a series of hypotheses on the variables on which it depends (e.g demand forecasts, fares, etc.). For each possible scenario there can be different NPVs.

In an attempt to incorporate the uncertainty of the values assumed from the variables, with a risk analysis it is necessary to associate to each critical variable, identified by means of a sensitivity analysis, a probability distribution, defined in a precise interval of values around the best estimate used in the basic case for calculating the NPV.

For each variable, the probability distribution can derive from diverse sources. The most common is made up of results from experimental studies carried out to find the desired values in situations as similar to the project as possible.

To this end, in our particular case a series of historical data were taken into consideration concerning the traffic served by the Municipal Transport Company of Catania, that provides a public bus service and has been assumed as a statistically important sample of the variability of demand for transport on the underground line. 
The historical traffic data were statistically analysed in order to obtain the probability distribution function best suited to the sample. To that end a Maximum Likelihood method was used. Once the distribution function $\mathrm{f}(\mathrm{x}) \mathrm{has}$ been fixed with parameter $\alpha$ and a series of $\mathrm{n}$ values of the sample $\mathrm{Xi}$, the method is based on the definition of the Likelihood expressed as:

$$
L=\prod_{i=1}^{n} f\left(X_{i}, \alpha\right)
$$

Setting the derivative of $L$ equal to zero with respect to the parameter $\alpha$, the value of the parameter giving the maximum probability of distribution to the data sample is determined. This means, in other words, maximising the product of the probability of the single events, that is the probability that all the events happen simultaneously. The method can be extended to include other parameters.

Figure 12 allows the cumulative frequency distribution of the historical traffic data to be compared with a normal distribution curve having a mean of 46.6680 , deviation standard of 3.6359 and variation coefficient percentage equal to $7.81 \%(3.6359 / 46.6680 \%)$.

Figure 13 shows a similar result for the variable 'public transport fare'.

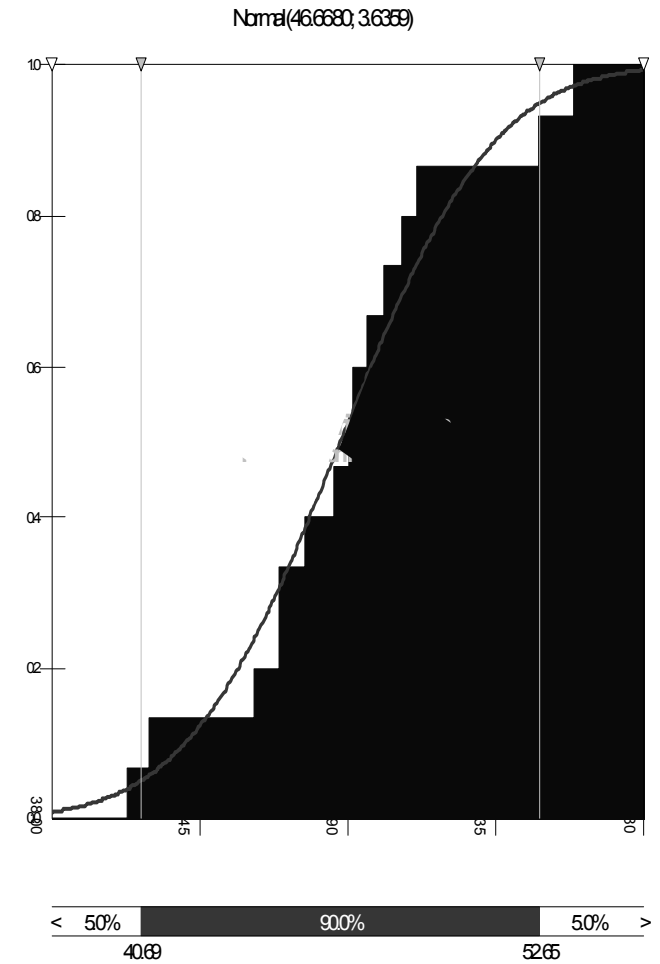

Figure 12. Cumulative probability distribution of demand for urban public transport in Catania

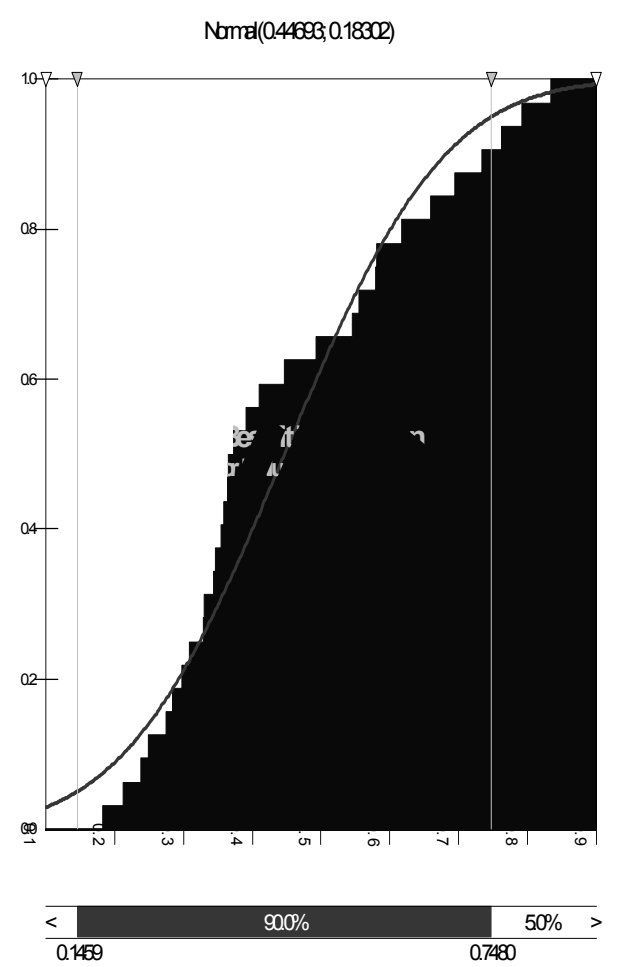

Figure 13. Cumulative probability distribution of the urban public transport fares in Catania

\subsection{The Montecarlo Method}

After having established the probability distribution of the critical variables the probability distribution of the NPV of the project can be calculated.

As has been said, with this aim, analyses are made using the Montecarlo method. This is a numerical analysis method developed in 1940 based on the use of the computer. It uses statistical sampling techniques to obtain probabilistic approximations for the solution of a mathematical model. 
The Montecarlo analysis was carried out using suitable calculation software. This is a macro written in the internal language of Microsoft Excel which functions as an added component in the working environment of the same software.

The software performs a repeated random extraction of a set of values of the critical variables, taken from within the respective definition intervals and carries out the calculation of the NPV deriving from each group of values extracted.

Obviously, the extraction of the values of the critical variables is carried out taking care that the frequency of presentation of the values extracted from the variables respects the predetermined probability distribution. Repeating the procedure for a sufficient number of extractions it is possible to obtain the convergence of the calculation towards a NPV probability distribution.

The probability distributions and the relative parameters used are those deriving from the previous paragraphs, considering that the hypothesis of being able to assign the same variation coefficient to the demand and fare variables of the underground line is reasonable (percentage relationship between standard and average deviation) taken from the probabilistic analysis of demand and fare data regarding urban public bus transport in Catania.

For the 'total demand' variable we use, therefore, a normal probability distribution with mean equal to the estimated value in the basic case $(38,306,68$ per annum) and standard deviation equal to $8 \%$ of the mean. In practice the simulation extracts the single demand components (private transport deviation, public transport deviation and generated) from a probability distribution that has mean values equal to those estimated for the basic case and standard deviation at the rate of percentage fraction that the demand component represents compared to the total.

As regards the relationship between the input variables, the relationship between the served demand and running costs and between the applied fare and the related expressed demand have been incorporated into the calculation model. The running costs therefore modify their value according to each random extraction of the demand, while due to the elasticity of demand compared to the fare, a different mean value of demand corresponds to each extraction of the fare.

Thus, in short, the Montecarlo method applied to the calculation model of the NPV proceeds with the following steps:

1. random extraction of a value of the fare for a one-way ticket (non-season ticket holder) from a normal distribution with a 0.77 euro mean and standard deviation equal to $20 \%$ of 0.77 .

2. calculation of the value of the season ticket fare in fixed relationship compared to the one-way ticket fare (monthly season ticket price is equal to about 20 times the price of a one-way ticket)

3. calculation of the mean value of the total demand related to the fare value extracted

4. random extraction of a total demand value of a normal distribution with a mean equal to that calculated in the previous step and standard deviation equal to $8 \%$ of the same

5. calculation of the running costs related to the demand value extracted in the previous step and calculated for each year of service life

6. calculation of the total costs

7. calculation of the gross and net revenue

8. discounting of net proceeds and calculation of the NPV

The algorithm described above was applied using 1000 iterations, thus obtaining 1000 NPV values. By means of a statistical analysis of the data obtained the probability distribution of the NPV is drawn up.

The result is obviously influenced both by the form of the probability distribution of the input variables and by the relative parameters (mean and standard deviation) used to calculate the NPV.

To verify the stability of the result, the procedure was carried out again using a triangular distribution for the input variables (demand and fare) and a uniform distribution with equal mean and standard deviation of the normal distribution. This is obtained assigning the parameters to the distribution according to Table 1 . 
Table 1. Parameters of three different probability distribution that have been used for the risk analysis

\begin{tabular}{ll}
\hline Type of distribution & Parameters of the distribution \\
\hline normal & $\mu, \sigma$ \\
triangular & $\mu-\sqrt{6} \sigma, \mu, \mu+\sqrt{6} \sigma$ \\
uniform & $\mu-\sqrt{3} \sigma, \mu+\sqrt{3} \sigma$ \\
\hline
\end{tabular}

Figure 14 shows the reciprocal relationship of the three normalised distributions, all with a mean 0 and standard deviation 1.

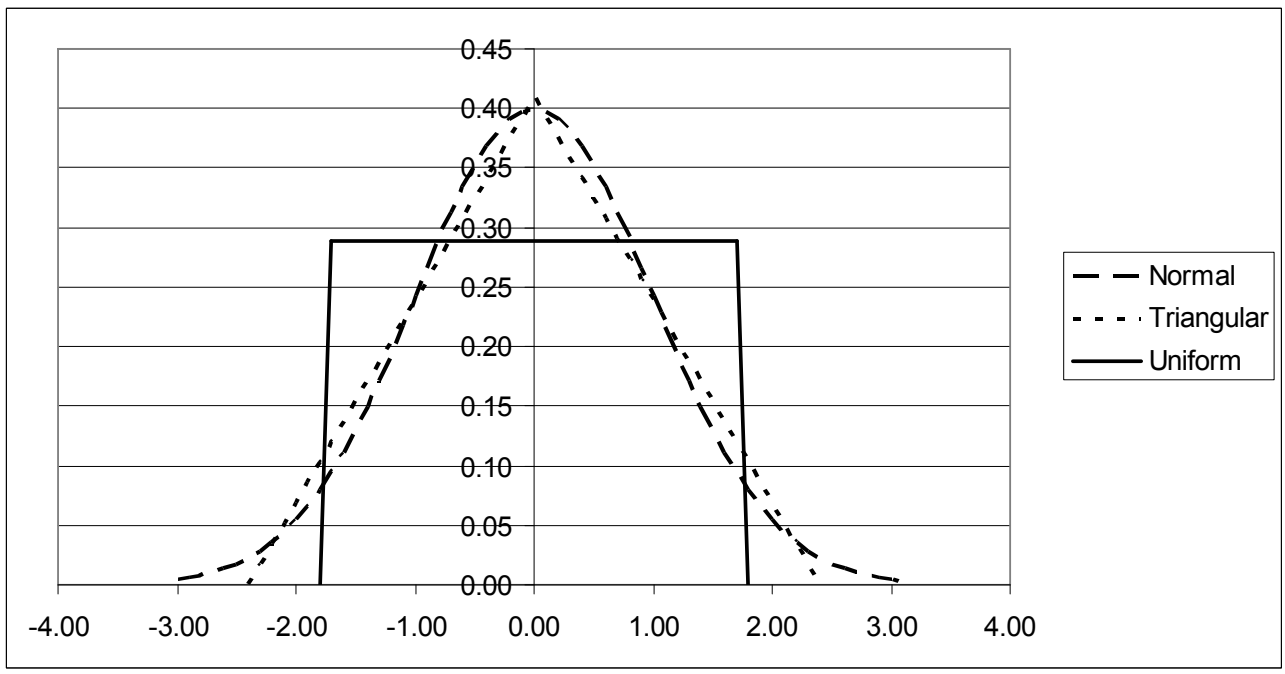

Figure 14. Probability distribution

Table 2 shows the main results of the risk analysis in terms of Net Present Value for three different probability distribution and two coefficient of variation

Table 2. Results of the risk analysis

\begin{tabular}{|c|c|c|c|c|c|c|c|}
\hline & \multirow{2}{*}{$\begin{array}{l}\text { Type of } \\
\text { distribution } \\
\text { Coefficient of } \\
\text { variation }\end{array}$} & \multicolumn{2}{|c|}{ normal } & \multicolumn{2}{|c|}{ triangular } & \multicolumn{2}{|c|}{ uniform } \\
\hline & & $8 \%$ & $16 \%$ & $8 \%$ & $16 \%$ & $8 \%$ & $16 \%$ \\
\hline \multirow{2}{*}{$\begin{array}{l}\text { NPV without public } \\
\text { funds (M€) }\end{array}$} & Mean & -238.19 & -238.44 & -238.08 & -238.35 & -238.00 & -238.25 \\
\hline & Standard deviation & 17.90 & 18.69 & 17.24 & 18.03 & 16.79 & 17.57 \\
\hline \multirow{2}{*}{$\begin{array}{l}\text { NPV with public } \\
\text { funds (M€) }\end{array}$} & Mean & -2.86 & -3.11 & -2.76 & -3.02 & -2.68 & -2.92 \\
\hline & Standard deviation & 17.90 & 18.69 & 17.24 & 18.03 & 16.79 & 17.57 \\
\hline
\end{tabular}

Both in the case of investments financed with a contribution from public funds (EU, State and Regional Funds), and in the case of no contributions, the NPV result is substantially stable, that is little influenced by the type of probability distribution used for the input variables (demand and fare). The result appears stable also when compared to the variability of demand. In effect, a doubling of the standard deviation of demand (from $8 \%$ to $16 \%$ of the mean value), produces an increase in the standard deviation of the NPV of about $3 \%$, while the NPV mean, constant in the case of no contributions, presents a variation of $9 \%$ when there are contributions. 
Instead, the NPV calculated in the basic case, that is using the best deterministic estimate as the value of the input variables, supplies a NPV of -235.35 million euros when there are no contributions and -0.02 million euros with contributions.

Figure 18, Figure 19 and Figure 20 show the results of the risk analysis carried out with the Montecarlo method in the different hypotheses that have been described are analytically reported.

\begin{tabular}{lllr} 
RiskSim - One Output - Summary & Mean & -238.19 \\
Date & $11-f e b-04$ & St. Dev. & 17.90 \\
Time & \multicolumn{1}{l}{7.59} & Mean St. Error & 0.57 \\
Workbook & ACB Fin prova Montecarlo.xls & Minimum & -321.19 \\
Worksheet & ACB Fin Random & First Quartile & -248.38 \\
Output Cell & \$AV $\$ 43$ & Median & -235.51 \\
Output Label & VAN (Meuro) & Third Quartile & -225.51 \\
Seed & 0.5 & Maximum & -201.14 \\
Trials & 1000 & Skewness & -1.0610
\end{tabular}
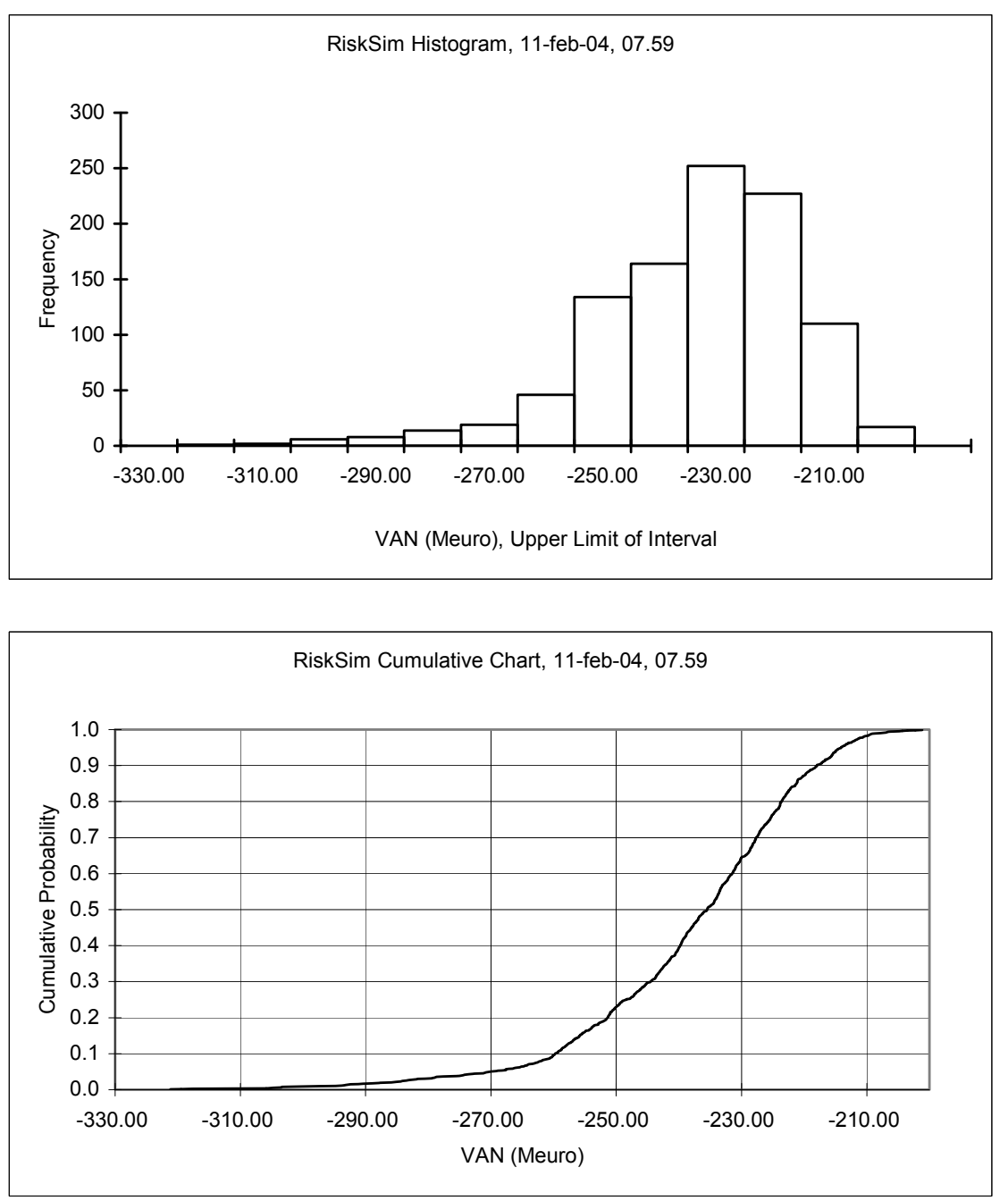

Figure 18. Results of risk analysis in the case of normal distribution 
RiskSim - One Output - Summary

Date 11-feb-04

Time 8

Workbook ACB Fin prova Montecarlo.xls

Mean

$-238.08$

Worksheet ACB Fin Random

St. Dev.

Output Cell \$AV\$43

Output Label VAN (Meuro)

Seed

0.5

Trials $\quad 1000$

Mean St. Error $\quad 0.55$

Minimum $\quad-291.71$

First Quartile $\quad-249.12$

Median $\quad-235.51$

Third Quartile $\quad-225.02$

Maximum $\quad-203.85$

Skewness $\quad-0.6328$
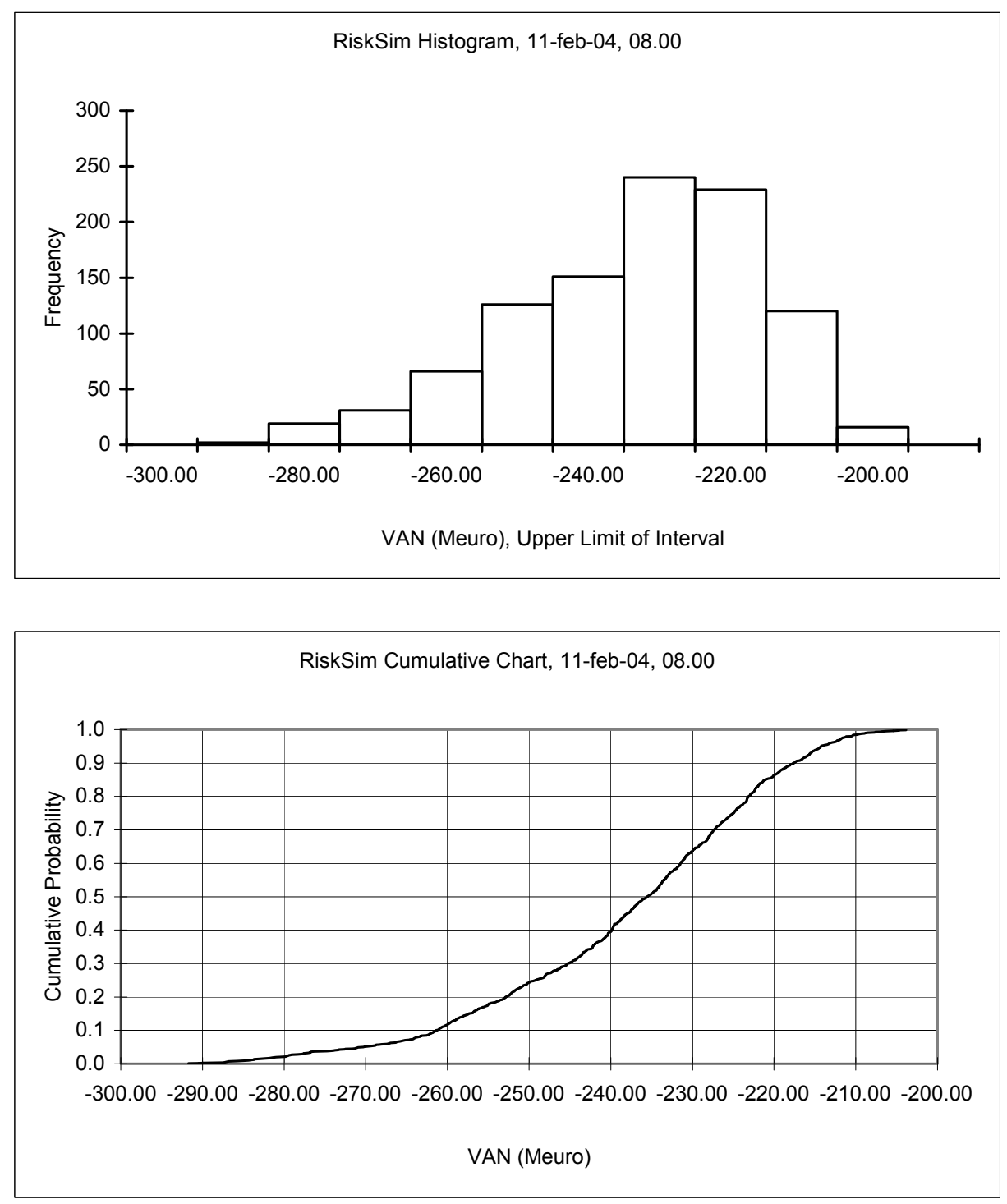

Figure 19. Results of risk analysis in the case of triangular distribution 


\begin{tabular}{lllr} 
RiskSim - One Output - Summary & Mean & -238.00 \\
Date & 11-feb-04 & St. Dev. & 16.79 \\
Time & \multicolumn{1}{c}{8.01} & Mean St. Error & 0.53 \\
Workbook & ACB Fin prova Montecarlo.xls & Minimum & -272.02 \\
Worksheet & ACB Fin Random & First Quartile & -252.26 \\
Output Cell & \$AV $\$ 43$ & Median & -235.59 \\
Output Label & VAN (Meuro) & Third Quartile & -224.00 \\
Seed & 0.5 & Maximum & -206.39 \\
Trials & 1000 & Skewness & -0.2910
\end{tabular}
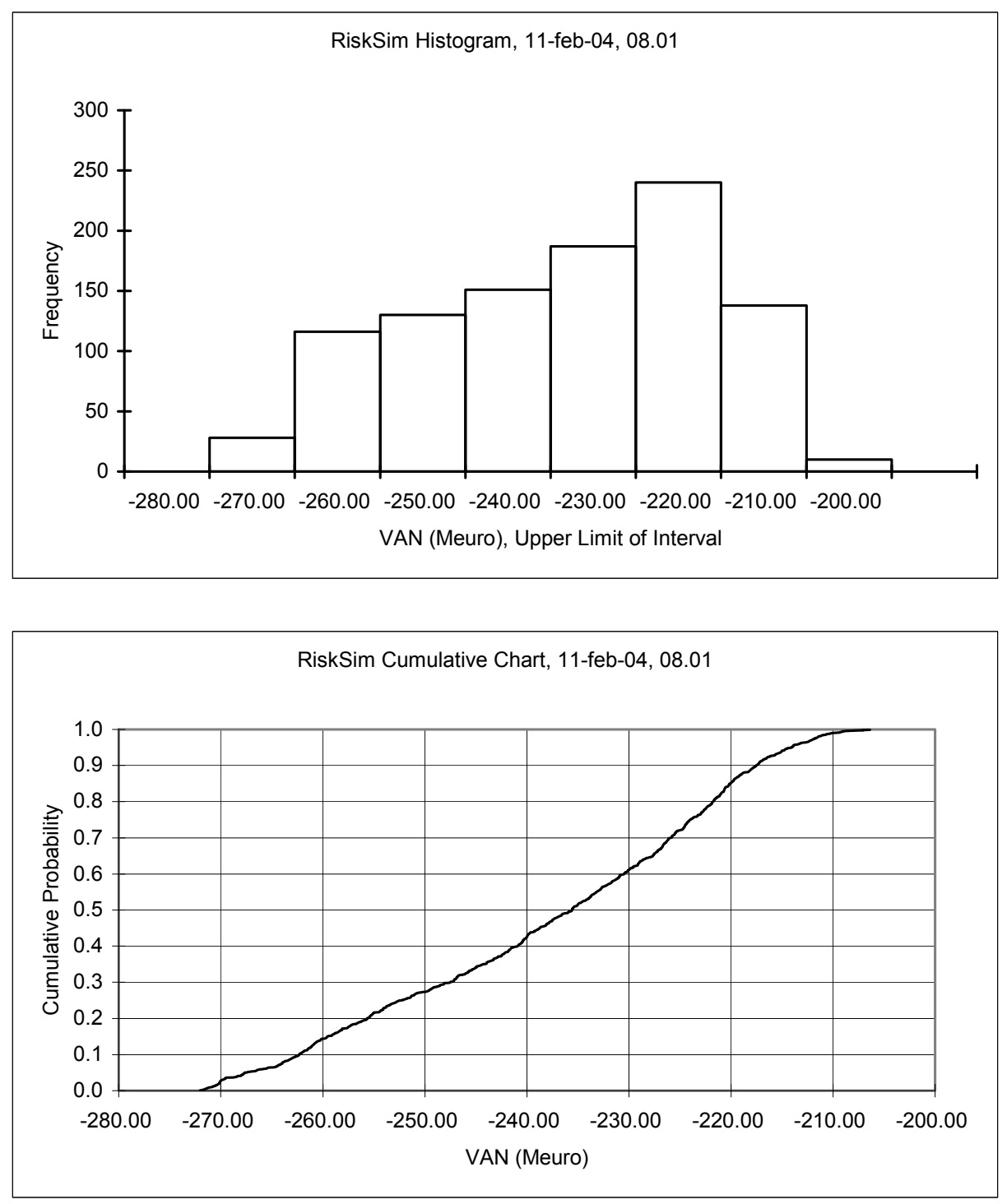

Figure 20. Results of risk analysis in the case of uniform distribution

\section{Conclusions}

The use of risk analysis applied to transport infrastructure projects proves to be a useful means of evaluating the appropriateness of an investment when there is a high uncertainty regarding the variables at stake. Thanks to the analysis results it is possible to define a project as risky in the case in which there is a high probability that the project will not go above a certain threshold of NPV or IRR. For example, whenever the probability distribution of the NPV of a project has a positive mean value but a high standard deviation of the same, two distinct decisions could be arrived at: 
To obtain further knowledge and analyses regarding the input variables of the financial analysis, with the aim of reducing the uncertainties and as a consequence reducing the variability of the NPV probability distribution.

To evaluate negatively the financial feasibility of the project as being too risky.

Whenever two projects competing for limited financial resources must be evaluated, it is necessary to find useful criteria to compare a project with a high value of mean NPV but with a high deviation standard and a project with an inferior mean NPV but with values outside the mean much less scattered around the same..

For example, Figure 15 shows the probability density functions of the NPV of two projects; project A has a mean NPV of 100 with a standard deviation of 20, while project B has a lower mean NPV, equal to 80 and a standard deviation of 10. Even though it has a higher mean NPV project A is more risky. In fact, as can be seen in Figure 16, the probability of having a NPV equal to at least 100 is equal to $50 \%$ for project A and almost $98 \%$ for project B which therefore appears as preferable from the risk point of view.

In a wider context, with the aim of evaluating both the economic and financial results of the analyses, it is necessary to take into consideration, as Figure 17 shows, the compromise that should be made between projects with a high financial risk but also high social benefits and, on the contrary, projects with a low financial risk but reduced social benefits.

Probability density

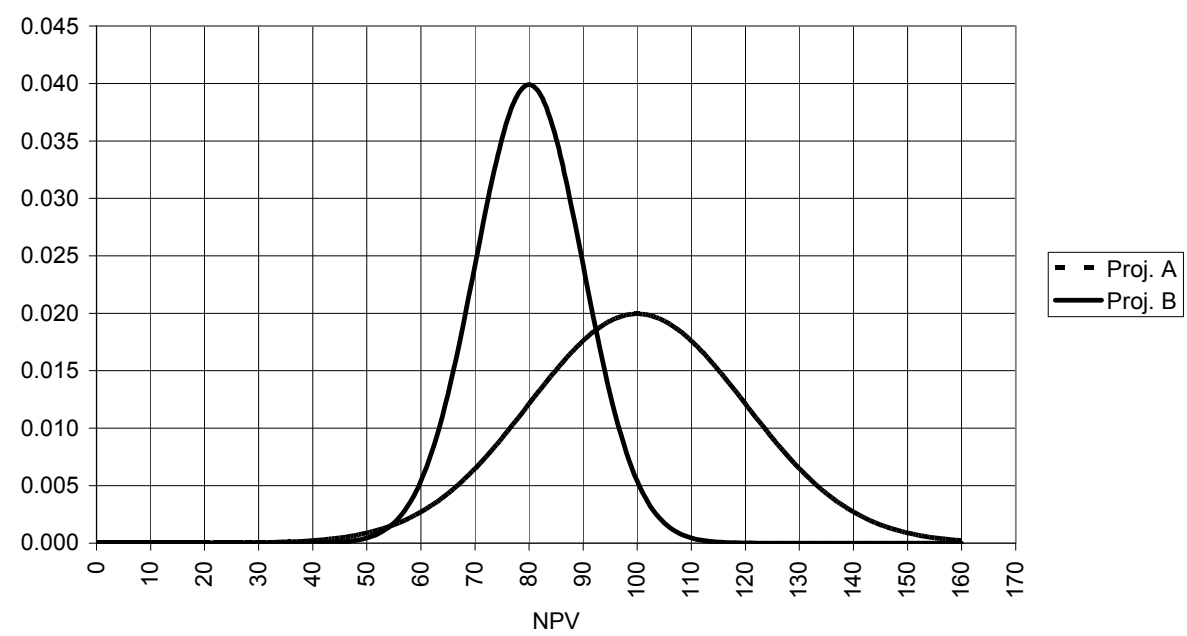

Figure 15. probability density functions of the NPV of two projects

Probability distributions

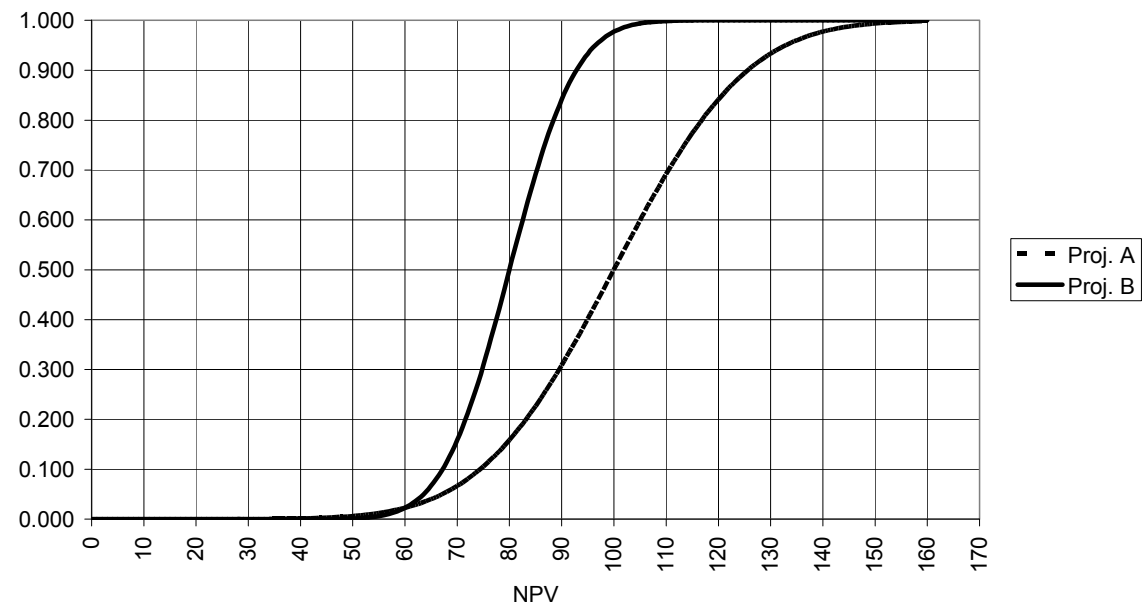

Figure 16. probability distribution functions of the NPV of two projects 


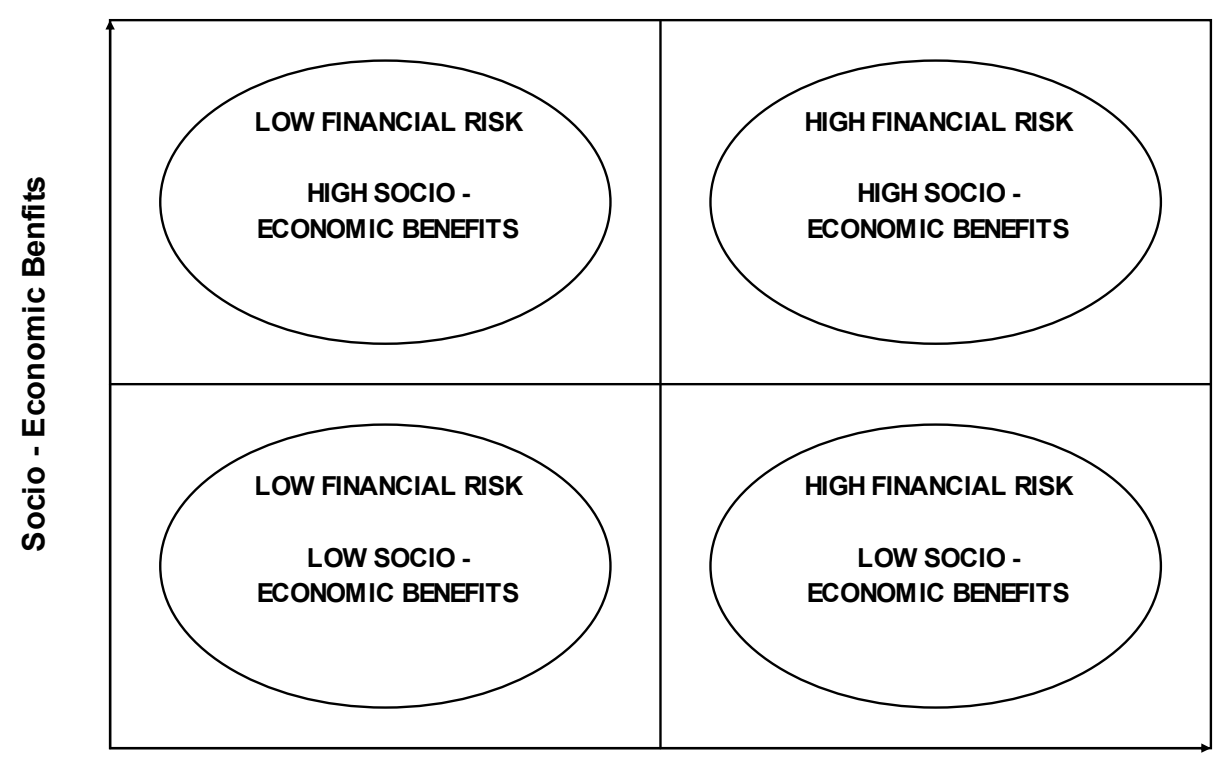

Financial Risk

Figure 17. Project classification

\section{References}

Boardman, A. E. (2006). Cost-Benefit Analysis: concept and practice (3rd ed.). Pearson Prentice Hall, Upper Saddle River, New Jersey.

Cascetta, E. (2009). Transportation Systems Analysis. Springer.

De Luca, M. (2000). Manuale di Pianificazione dei Trasporti. Milano: Franco Angeli.

European Commission. (2006). Council Regulation (EC) No. 1083/2006. Retrieved from http://eur-lex.europa.eu/

European Commission. (2008). Guide to Cost-Benefit Analysis of investment projects. Retrieved February 19, 2012, from http://ec.europa.eu/regional_policy/sources/docgener/guides/cost/guide2008_en.pdf

Florio, M. (2007). Cost-Benefit Analysis and Incentives in Evaluation. The Structural Funds of the European Union, Edward Elgar, Cheltenham.

Isaksson, T. (2002). Model for estimation of time and cost based on risk valuation applied on tunnel projects. Doctoral Thesis, Division of Soil and Rock Mechanics - Royal Institute of Technology - Stockholm, Sweden.

Matas, A. (2004). Demand and Revenue Implications of an Integrated Public Transport Policy: The Case of Madrid. Transport Reviews, 24, 195-217.

Norris, C., Perry, J., \& Simon, P. (2000). Project Risk Analysis and Management. Association for Project Management. High Wycombe, UK.

Risk Assessment Forum. (1997). Guiding Principles for Monte Carlo Analysis. US Environmental Protection Agency, Washington. $\quad$ Retrieved from http://video.onset.freedom.com/jdn/10xq8z-principalsformontecarloanalysis.pdf

Saltelli, A. et al. (2008). Global Sensitivity Analysis. The Primer, John Wiley \& Sons. 